Борис НАУМОВ*, Вяйно ПУУРА*, Велло КАРИЗЕ*, Надежда КОРОЛЕВА**, Михаил ТЕРЕНТЬЕВ**, Анна КОЛОТВННА**

\title{
РАДОНОВЫЙ ФАКТОР РАДИАЦИОННОГО ФОНА В НАСЕЛЕННЫХ ПУНКТАХ СЕВЕРНОЙ ЭСТОНИИ (ЭКОГЕОЛОГИЧЕСКИЙ АСПЕКТ)
}

Изучением формирования природного и техногенного радиационного фона занимаются специалисты различных направлений. Зависимость радиационного фона от геологических факторов входит в поле зрения экогеологии. В данной статье сведены результаты изучения радонового фактора радиационного фона в Эстонии, проводимого Институтом геологии АН Эстонии в сотрудничестве со специализированными научными организациями начиная с 1984 г.

Согласно оценкам Научного комитета по действию атомной радиации (НКДАР) ООН, радон и его дочерние продукты (ДПР) в помещениях обусловливают в среднем примерно $75 \%$ от годовой эффективной эквивалентной дозы (ӘЭД) облучения населения от земных источников радиации и около $50 \%$ от всех естественных источников ионизирующего излучения (Радиация, 1988). Согласно рекомендациям Международной комиссии по радиационной защите, индивидуальная ЭЭД облучения человека радиоактивными веществами не должна превышать 5 мЗв (0,5 бэра) за любой под радиационного воздействия (Принципы нормирования, 1986). Годовая ӘЭД естественного фона в европейской части бывшего СССР колеблется от 0,7 до 2 мЗв, а в отдельных местах достигает 2-3 мЗв (Булдаков, 1986). По данным НИИ радиационной гигиены (НИИРГ), ежегодная доза человека на территории бывшего СССР составляет в среднем 1,5 мЗв от медицинского облучения и 2,9 м3в от природного фона, т. е. 4,4 мЗв (0,44 бэра) (Рамзаев, 1989). Повышенное выделение радона в атмосферу с земной поверхности (эксхаляция) имеет связь с содержанием радионуклидов уран-радиевого ряда в аномальных зонах, что, в свою очередь, определяется типом горных пород, почв и отложений, а также, в зоне их влияния, гидрогеологическими условиями (Лисаченко и др., 1984; Наумов, 1990) (табл. 1). Зоны тектонических разломов, трещиноватости, закарстованности и повышенной пористости пород увеличивают эксхаляцию радйоактивных эманаций (Газизов, 1989). Кроме того, свою долю в поступление радона в помещения или вообще в любое замкнутое пространство вносят строительные материалы, бытовой газ, вода (в основном в в душевых и ванных комнатах). При этом строительные материалы оказывают решающее влияние (табл. 2) в случае аномально высокого содержания в них естественных радионуклидов (радия-226, тория-228).

* Eesti Teaduste Akadeemia Geoloogia Instituut (Институт rеологии Академии наук Эстонии). Estonia pst. 7, EE-0105 Tallinn. Estonia.

** НИИ радиационной гигиены. Россия. 197101 Санкт-Петербург, ул. Мира 8. 
В Северной Әстонии имеются аномальные зоны с превышением содержания радия в почвах относительно основной части территории Эстонии в 4-10 раз и мощностью дозы гамма-излучения $0,2-0,38$ мкЗв/ч, а в отдельных точках в районах Нарвы, Силламяэ и Маарду достигающей $0,82-2,50$ мкЗв/ч (Наумов, 1990). В Южной Финляндии, тоже в основном вблизи Финского залива, выявлены 5-7-кратные аномалии по содержанию урана (радия) и тория с мощностью дозы гамма-излучения, в два и более раз превышающей минимальное фоновое значение. Здесь же зафиксированы и радоновые аномалии в воздухе помещений и в подземных водах (Juntunen, 1991; Lahermo, Juntunen, 1991). В Финляндии средняя годовая индивидуальная доза составляла в 1986 г. 4,54 мЗв при вкладе радона 48,5\% (Piispanen, 1991).

По способности к эксхаляции радона $\left(15 \mathrm{mБK} / \mathrm{m}^{2} \cdot \mathrm{c}\right)$ подзолистые почвы, распространенные на северо-западе Восточной Европы, близки к суглинкам и почвам Средней Азии, развитым в большинстве своем на лёссах и имеющим верхний предел эксхаляции $\left(19-20 \mathrm{mБк} / \mathrm{m}^{2} \cdot c\right)$, т. е. уступающим только скальным породам в отвалах $(34-39$ мБк/м².c). В этом отношении наиболее безопасны песчаные грунты и песчаники, а также пляжные пески Таллинна (табл. 1 и 2). Осадочные горные породы фосфоритовых месторождений Северной Әстонии - граптолитовый аргиллит, известняк, оболовый конгломерат и глауконитовый песчаник - содержат радий-226 в количествах, в 2,2-9 раз превышающих средние концентрации этого элемента в соответствующих аналогах других мест (табл. 2). В прибрежной полосе Финского залива в Эстонии эти породы наиболее близко подходят к земной поверхности и часто обнажаются в пределах глинта и современного берега, речных долин, бортов карьеров, строительных котлованов. Зоны тектонических разломов, карстовых проявлений, обнажений этих пород, зоны разгрузки подземных вод, испытывающих влияние перечисленных пород и факторов, обычно являются аномальными по эксхаляции радона. Увеличению эксхаляции способствуют и неотектонические движения, раскрывающие при подъеме Фенноскандии трещины, создающие новые разрывные нарушения в осадочном чехле и перераспределяющие внутрипоровое давление (Газизов, 1989).

При альфа-распаде радиоактивных ядер на каждый образовавшийся изотоп приходится атом гелия. Следовательно, данные положительных аномалий гелиевых съемок могут служить индикатором вероятного повышенного эманирования радона. По этому признаку, судя по данным карты гелиеносности Эстонии (Тибар, 1987), потенциально аномальные зоны имеются в северо-западном и северо-восточном прибрежных регионах (условно Таллиннский и Кохтла-Ярвеский), западном (обширная зона Килинги-Нымме-Пярну-Матсалу), центральном (в основном на запад от Тарту) и Чудско-Псковском прибрежном регионах (близ Муствеэ и Ряпина-Вярска), а также на Западно-Әстонском архипелаге (южная часть о-вов Хийумаа и Сааремаа, о-в Муху).

Деятельность человека вызывает заметное изменение природного фона радиации, создавая в отдельных регионах разных стран техногенно-усиленный фон, имеющий тенденцию к росту в основном за счет эманаций радона и торона. Вклад торона и его дочерних продуктов (ДПТ) составляет при этом $20 \%$ от радона и ДПР, но в отдельных случаях этот вклад может быть основным в суммарной ӘӘД облучения людей (Шалак и др., 1982).

Как видно из вышеизложенного, отдельные районы Эстонии, как правило, густонаселенные, имеют все основания быть причисленными к аномальным по эксхаляции радона и, следовательно, его повышенному накоплению в помещениях и отрицательному воздействию на здоровье человека. 
Әксхаляция радона с земной поверхности различными почвами (Мосинец и др., 1991)

Table 1

Exhalation of radon from the earth's surface by different soils (Мосинец et al., 1991)

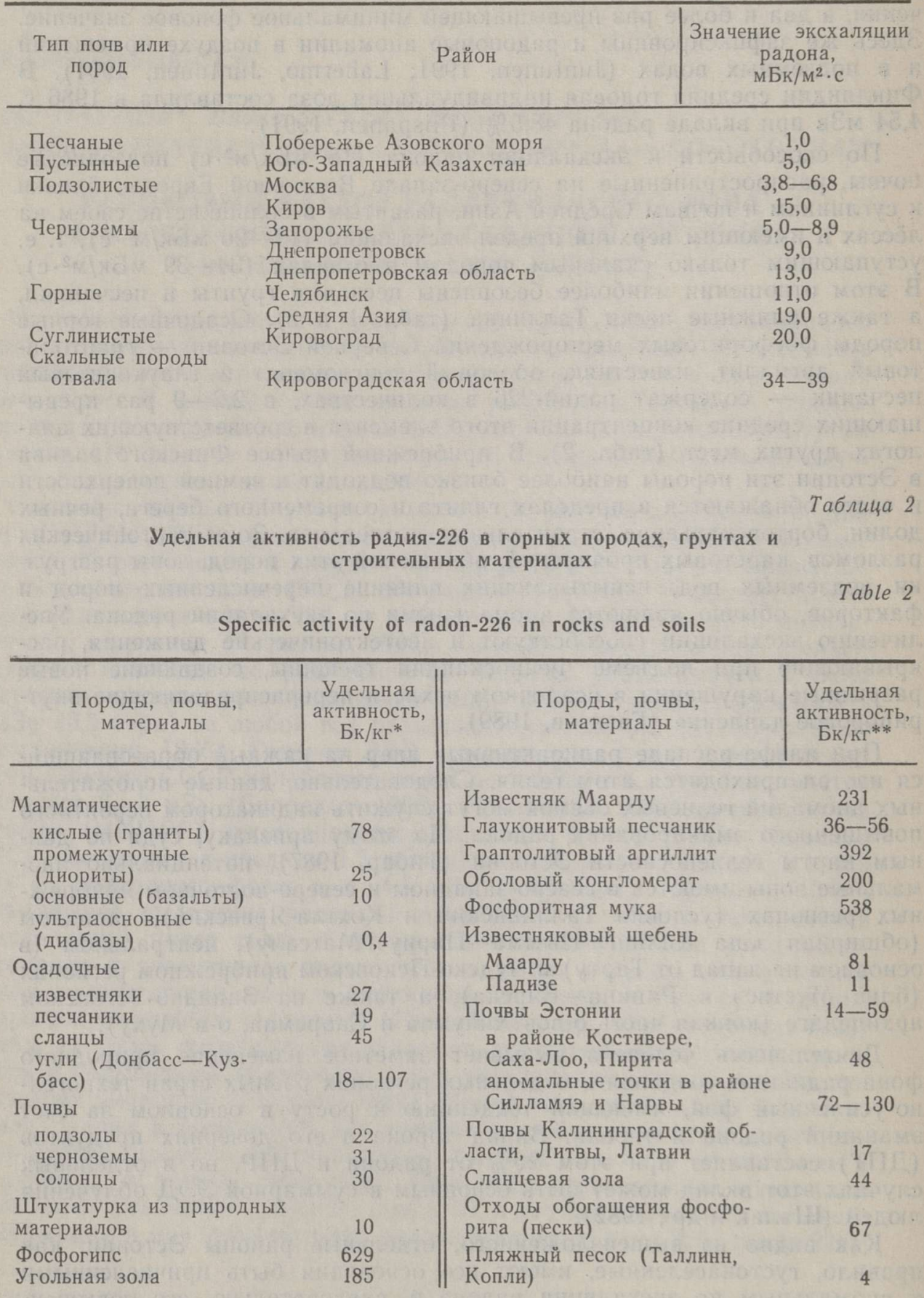

* Данные В. М. Мосинца и др. (1991), В. Ф. Дричко и др. (1977).

** Наши данные. 
Для оценки радонового фактора радиационного фона в северной, прибрежной полосе Әстонии проведены измерения объемной активности (концентрации) радона $C_{\mathrm{Rn}}$ в воздухе подвальных и полуподвальных помещений, жилых и производственных зданий в Нарве, Силламяэ, Кохтла-Ярве, Юлгазе, Маарду и Таллинне (Наумов, 1990). Всего проведено 114 интегральных измерений в 110 точках с суммарным временем экспозиции 1062 суток.

В исследованиях применяли в основном угольные пассивные диффузионные пробоотборники радона (ПДПР) сорбционного типа, а также интегральные трековые детекторы радона (ИТДР). Время экспозиции ПДПР составляло 5-7 сут., ИТДР - 1,5-2 мес. (Крисюк, Лихтаров, 1991; Крисюк и др., 1982). Минимальная измеряемая объемная активность радона $C_{\mathrm{Rn}}$ в случае применения ПДПР составляла 7,4 Бк $/ \mathrm{M}^{3}$, в случае применения ИТДР нитроцеллюлозного типа 15 Бк/м³. Среднее значение объемной активности радона- 222 за время экспозиции определяли для пробоотборников типа ПДПР при помощи сцинтилляционного гамма-спектрометра СГС-200. Трековые детекторы ИТДР подвергали после окончания экспозиции травлению в специальном растворе и затем подсчитывали число треков методом искрового счета на счетчике Радиевого института им. Хлопина.

Калибровку, поверку и исследование характеристик проводили на установке, состоящей из бокса 1БП-20С объемом 800 л, радиометра РГБ-07 и набора образцовых растворов радия, позволяющих создавать в боксе объемную активность радона от 500 до 50000 Бк/м ${ }^{3}$. Методика и аппаратура разработаны в НИИРГ.

Достаточно длительная экспозиция пробоотборников и детекторов в сочетании с их установкой в холодное и теплое время года соответственно со слабым или с относительно интенсивным проветриванием помещений позволили оценить среднегодовые значения объемной активности радона в воздухе помещений и в атмосфере.

Места установки пробоотборников и детекторов выбирали таким образом, чтобы получить информацию об объемной активности радона в зависимости от типа сооружений и помещений, строительного материала, геологических условий и степени заглубленности помещений.

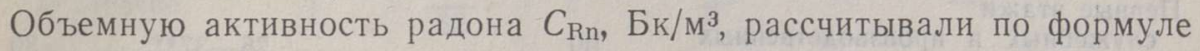

$$
C_{\mathrm{Rn}}=A / K T \text {, }
$$

где $A$ - активность адсорбированного радона за время экспозиции, Бк; $T$ - время экспозиции, сут.; $K$ - калибровочный коэффициент.

ЭӘД рассчитывали с использованием дозовых коэффициентов, рекомендуемых НКДАР ООН, коэффициента равновесия между радоном и его ДПР $\left(K_{\mathrm{p}}=0,5\right)$, а также вероятного или фактического времени пребывания в тех или иных помещениях. Результаты интерпретировали, применяя данные, полученные в Әстонии (Лисаченко и др., 1984; Наумов, 1990), в горной местности Кыргызстана, в Бишкеке (Наумов, 1990) и в условиях севера Русской платформы, в Новгороде, а также в Финляндии (Juntunen, 1991; Piispanen, 1991).

Результаты измерений $C_{\mathrm{Rn}}$ ниже и выше уровня поверхности земли в городах Северной Эстонии в сравнении с Бишкеком и Новгородом (табл. 3,4$)$ показали, что наибольшему накоплению радона подвержены подземные сооружения - шурфы и колодцы, а также подвалы и погреба, имеющие, как правило, 4-5 поверхностей контакта с грунтами, слабую изоляцию стен и пола или ее отсутствие, а также полное или почти полное отсутствие вентиляции. Объемная активность радона в подземных сооружениях в известной мере отражает способность местных грунтов эманировать радон, 
На первых этажах зданий превалируют эксхаляция радона земной поверхностью и эманирование радона в основном строительными материалами, а на верхних этажах - главным образом строительными материалами. Следовательно, эманирующая способность грунтов наиболее высока в регионе Кохтла-Ярве-Силламяэ-Нарва (1758-2180 до 3430 Бк $/ \mathrm{m}^{3}$ ) и несколько ниже в районе Маарду-Юлгазе-Таллинна $\left(252-1715\right.$ до $\left.3404 \mathrm{Бk} / \mathrm{m}^{3}\right)$. Уровень накопления радона на первых этажах в среднем в 24 раза ниже, но в помещениях зданий, построенных из известняка и слабо проветриваемых, объемная активность

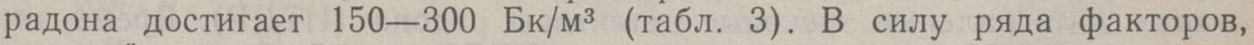
главный из которых - проветривание, накопление радона в квартирах ниже, чем в служебных и производственных помещениях (11-46

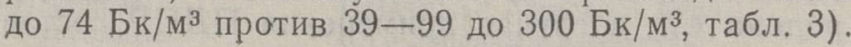

Таблица 3

Объемная активность радона $C_{\mathrm{Rn}}$ в городах Северной Эстонии (числитель - среднее, знаменатель - диапазон значений), Бк/м³

Table 3

Volume activity of radon $C_{R n}$ in excavations, wells, and buildings of North Estonia (numerator - mean, denominator - range of values), $\mathrm{Bq} / \mathrm{m}^{3}$

\begin{tabular}{c|c|c|c|}
\hline Место замеров & Нарва & $\begin{array}{c}\text { Кохтла-Яр- } \\
\text { ве, Силла- } \\
\text { мяэ }\end{array}$ & $\begin{array}{c}\text { Маарду- } \\
\text { Юлгазе }\end{array}$ \\
\hline
\end{tabular}

Шурфы и колодщы глубиной $0,5-2 \mathrm{M}$

Подвалы, полуподвалы, погреба

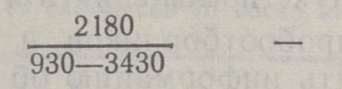

$$
\begin{aligned}
& \frac{1715}{27^{*}-3404}= \\
& \frac{104}{7-370}
\end{aligned}
$$$$
\frac{456}{9-1620} \quad \frac{1758}{444-3071}
$$

Первые этажи

служебных и производственных помещений

жилых помещений

Приповерхностный слой атмосферы

Количество измерений

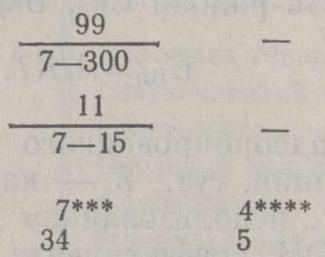

$$
\begin{array}{cc}
\frac{26-37^{* *}}{4-100} & \frac{39}{7-150} \\
\frac{46}{4-74} & \frac{19}{7-56}
\end{array}
$$

$\overline{21}$

$\overline{54}$

* Қолодец с бетонными стенками в Мууга.

** Цехи ПО Эстонфосфорит, проветривание хорошее.

*** В нише под известняковой плитой $670 \mathrm{БK} / \mathrm{m}^{3}$.

**** Под полиэтиленовой пленкой $85 \mathrm{БK} / \mathrm{m}^{3}$.

Изучение распределения объемной активности радона по вертикали от шурфов и подвалов до верхних этажей зданий во всех рассматриваемых здесь регионах Эстонии, России и Кыргызстана дало цифры 1542-1948 до 8-15 Бк/м³ (табл. 4). 
Распределение значений объемной активности радона $C_{\mathrm{Rn}}$ по вертикали в Северной Әстонии и других регионах (числитель - среднее, знаменатель максимум)

Table 4

Vertical distribution of radon volume activity $C_{\mathrm{Rn}}$ in North Estonia and other regions (numerator - mean, denominator - maximum values)

\begin{tabular}{|c|c|c|c|c|c|c|c|}
\hline \multirow{2}{*}{$\begin{array}{c}\text { Тип простран- } \\
\text { ства, поме- } \\
\text { щения }\end{array}$} & \multicolumn{2}{|c|}{$\begin{array}{l}\text { Северная } \\
\text { Әстония }\end{array}$} & \multicolumn{2}{|c|}{$\begin{array}{c}\text { Кыргызстан, } \\
\text { Бишкек }\end{array}$} & \multicolumn{2}{|c|}{$\begin{array}{l}\text { Россия, } \\
\text { Новгород }\end{array}$} & \multirow{2}{*}{$\begin{array}{c}\text { Швеция, } \\
\text { Финляндия } \\
\text { (Радиация, } \\
1988), \text { Бк/м³ }\end{array}$} \\
\hline & $\begin{array}{c}\text { коли- } \\
\text { чество } \\
\text { заме- } \\
\text { ров }\end{array}$ & $\begin{array}{l}C_{\mathrm{Rn},}, \\
\mathrm{5K} / \mathrm{M}^{3}\end{array}$ & $\begin{array}{c}\text { коли- } \\
\text { чество } \\
\text { заме- } \\
\text { ров }\end{array}$ & $\begin{array}{l}C_{\mathrm{Rn}}, \\
\mathrm{EK} / \mathrm{M}^{3}\end{array}$ & $\begin{array}{c}\text { коли- } \\
\text { чество } \\
\text { заме- } \\
\text { ров }\end{array}$ & $\begin{array}{l}C_{\mathrm{Rn}}, \\
\mathrm{GK} / \mathrm{M}^{3}\end{array}$ & \\
\hline
\end{tabular}

Ниже поверх-

ности земли

$\begin{array}{lcccccc}\begin{array}{l}\text { шурфы, } \\ \text { колодцы }\end{array} & 6 & \frac{1948}{3430} & 3 & \frac{1542}{4440} & - & - \\ \text { подвалы } & 37 & \frac{642}{3071} & 4 & \frac{1302}{4440} & 2 & \frac{65}{120}\end{array}$

Выше поверх-

ности земли

1-е этажи, служебные и рабочие

1-этажи,

жилые

2-е этажи, служебные и рабочие

2-е этажи, жилые

3-е этажи, служебные и рабочие

3-е этажи, жилые

29

15

6

$\begin{array}{lll}\frac{45}{100} & 4 & \frac{23}{28}\end{array}$

$\begin{array}{lll}\frac{57}{300} & 13 \quad \frac{40}{81}\end{array}$

$15 \quad \frac{25}{74} \quad 6 \quad 63$

27

$\frac{13}{37} \quad \frac{\approx 100-160}{>10000}$

\section{$\frac{23}{28}$}

$16 \quad \frac{11}{27}$

$5 \quad \frac{15}{52} \quad 1$

6

$\frac{8}{12}$

4-8-e

этажи

Приповерхност-

ный слой

атмосферы
4
1

15

30

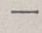

5

$6 \quad \frac{6^{*}}{7} \quad 9 \quad \frac{8^{* *}}{12} \quad-$

* Слой воздуха $0-0,1$ м; ** слой воздуха $0-2$ м.

Прибрежная зона Северной Эстонии сложена коренными породами кембрия и ордовика, Бишкек (включая ущелье Ала-Арча до 2000 м над уровнем моря) испытывает влияние пород гранитоидного состава и палеоген-неогеновых отложений, а Новгород расположен на осадочном чехле девонской равнины. Северное побережье Финского залива и Скандинавия в целом в большей степени, чем Эстония, испытывают влияние кристаллического щита из-за меньшей мощности осадочных 
пород или их отсутствия. Именно поэтому в Швеции и Финляндии сами природные условия способствуют ощутимому накоплению радона на первых этажах зданий - в среднем 100-160 до 10000 Бк/ $\mathrm{m}^{3}$ и более против 25-57 до $300 \mathrm{БK} / \mathrm{m}^{3}$ в Северной Эстонии, 40-63 до $115 \mathrm{Бк} / \mathrm{m}^{3}$ в Бишкеке и 13 до 37 Бк/м³ в Новгороде (табл. 4).

По накоплению радона в подземных сооружениях и шурфах также можно говорить о том, что Северная Әстония - регион с повышенной способностью грунтов и горных пород к эманированию радона, находящийся в этом отношении на одном уровне с Бишкеком, но значительно превосходящий по уровню Новгород: 642-1948 и $1302-1542$ Бк/м ${ }^{3}$ против 65 Бк $/ \mathrm{M}^{3}$ (табл. 4). Долевое распределение результатов измерений объемной активности радона по шкале 50, 100 и 200 Бк/м ${ }^{3}$ с учетом данных других авторов (Jõgioja и др., 1990) подтверждает этот вывод (табл. 5),

Таблица 5

Долевое распределение значений объемной активности радона в городах Әстонии, России и Қыргызстана, \%

Table 5

Longitudinal distribution of radon volume activity in some towns of Estonia, Russia, and Kyrgyzstan, \%

\begin{tabular}{|c|c|c|c|c|c|c|c|c|}
\hline \multirow{2}{*}{ Место замеров } & \multirow{2}{*}{ 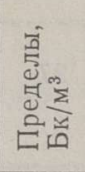 } & \multirow{2}{*}{ 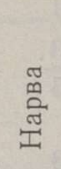 } & \multirow{2}{*}{ 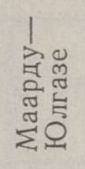 } & \multirow{2}{*}{ 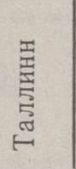 } & $\begin{array}{l}\text { Тапа- } \\
\text { Кунда }\end{array}$ & Тарту & \multirow{2}{*}{$\begin{array}{l}5 \\
0 \\
0 \\
0 \\
0 \\
0 \\
0 \\
0 \\
\text { I. }\end{array}$} & \multirow{2}{*}{ 苟 } \\
\hline & & & & & \multicolumn{2}{|c|}{$\begin{array}{c}\text { (Jõgioja и др., } \\
1990)\end{array}$} & & \\
\hline Подвалы & $\begin{array}{r}50 \\
100 \\
200\end{array}$ & $\begin{array}{l}60 \\
40 \\
40\end{array}$ & $\begin{array}{l}71 \\
57 \\
43\end{array}$ & $\begin{array}{l}44 \\
41 \\
33\end{array}$ & ב & $\bar{z}$ & $\begin{array}{r}50 \\
50 \\
0\end{array}$ & $\begin{array}{r}100 \\
100 \\
50\end{array}$ \\
\hline $\begin{array}{l}\text { Первые этажи } \\
\text { помещений }\end{array}$ & $\begin{array}{r}50 \\
100 \\
200\end{array}$ & $\begin{array}{l}42 \\
33 \\
17\end{array}$ & $\begin{array}{r}56 \\
0 \\
0\end{array}$ & $\begin{array}{c}24 \\
9,5 \\
0\end{array}$ & $\begin{array}{l}45-52 \\
27-24\end{array}$ & $\begin{array}{r}\overline{11} \\
6\end{array}$ & $\begin{array}{l}0 \\
0 \\
0\end{array}$ & $\begin{array}{r}65 \\
12 \\
0\end{array}$ \\
\hline $\begin{array}{l}\text { Верхние этажи } \\
\text { помещений }\end{array}$ & $\begin{array}{r}50 \\
100 \\
200\end{array}$ & $\begin{array}{r}13 \\
7 \\
0\end{array}$ & $\overline{-}$ & $\begin{array}{l}0 \\
0 \\
0\end{array}$ & $\overline{-}$ & E & $\begin{array}{l}0 \\
0 \\
0\end{array}$ & $\begin{array}{r}18 \\
0 \\
0\end{array}$ \\
\hline Количество замеров & & 32 & 16 & 54 & 31 & 18 & 45 & 32 \\
\hline
\end{tabular}

Облучение людей радоном, тороном и их дочерними продуктами происходит главным образом ингаляционным путем. Поэтому опасность облучения человека радоном и ДПР (без учета торона и ДПТ) в обследованных городах была оценена с помощью расчета индивидуальной ЭЭД в зависимости от времени пребывания человека в данном помещении. Выяснилось, что в Северной Эстонии ЭЭД только за счет радона может превышать до четырех и более раз допустимую ЭЭД (5 м3в/год) при работе людей в подвальных и полуподвальных помещениях (табл. 6). В служебных и производственных помещениях различных зданий ӘӘД за счет радона в целом составляет $0,4-1,6$ до 3,8 мЗв/год (8-32 до $39-76 \%$ от предельной ЭЭД) при максимуме в отдельных, но типичных зданиях до 20,6-39 мЗв/год.

В Тапа, Силламяэ и Кунда ЭЭД за счет радона, рассчитанная по данным других авторюв (Jõgioja и др., 1990), также может составлять $6,8-13,8$ мЗв/год в жилых помещениях. 
Әффективные эквивалентные дозы облучения человека в городах Эстонии (числитель - среднее, знаменатель - диапазон значений), мЗв/год

Table 6

Effective equivalent radiation doses received by inhabitants in some Estonian towns (numerator - mean, denominator - range of values), $\mathrm{mSv} / \mathrm{yr}$

\begin{tabular}{c|c|c|c|c|c}
\hline Место замеров & Нарва & $\begin{array}{c}\text { Кохтла-Яр- } \\
\text { ве, Силла- } \\
\text { мяэ }\end{array}$ & $\begin{array}{c}\text { Маарду- } \\
\text { Юлгазе- } \\
\text { Мууга }\end{array}$ & Таллинн & $\begin{array}{r}\text { Другие } \\
\text { города** }\end{array}$ \\
\hline
\end{tabular}

Подвалы, полуподвалы, погреба***

Служебные и производственные помещения (1-е этажи)

Жилые помещения (1-е этажи)

$$
\frac{5,8}{0,1-20,6} \quad \frac{22,3}{5,6-39} \cdot \frac{1,3}{0,1-4,7} \quad \frac{3,2}{0,1-15,6}
$$

$\begin{array}{ccccc}\frac{1,3}{0,1-3,8} & - & \frac{0,3-0,5}{0,1-1,3} & \frac{0,5}{0,1-1,9} & - \\ \frac{0,4}{0,2-0,5} & 7,8^{* *} & \frac{1,6}{0,1-2,6} & \frac{0,7}{0,2-2} & \begin{array}{c}6,8 \\ 13,8 \text { (Тапа) } \\ \text { (Кунда) } \\ \text { (Тарту) }\end{array}\end{array}$

* Без учета вклада торона и ДПТ.

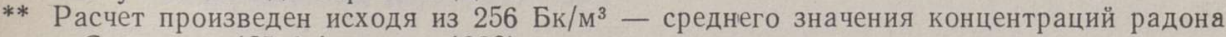
в Силламяэ (Jõgioja и др., 1990).

*** При условии пребывания человека 8 ч в каждые рабочие сутки.

Расчеты показывают, что вклад радона и ДПР в суммарную ЭЭД всех видов ионизирующего излучения колеблется от $7-9$ и $27-39 \%$ в районе Таллинн-Маарду-Юлгазе до $61-93 \%$ в регионе КохтлаЯрве-Силламяэ-Нарва.

\section{Выводы}

В Эстонии установлено выделение из земли в атмосферу радона в количествах, которые создают в помещениях радиационный фон, ощутимо превышающий допустимые нормы. Наибольшими концентрациями радона характеризуются северные районы Әстонии, особенно ЛяэнеВирумаа и Ида-Вирумаа, в меньшей степени - район ТаллиннМаарду.

Источниками радона являются или могут являться коренные породы, глубинные гелиеносные воды и газы, почвы, строительные материалы.

Степень интенсивности выделения радона из горных пород зависит от их состава, геологических условий и их физического состояния. В связи с этим граптолитовые аргиллиты и фосфориты Әстонии активнее других пород и выделяют больше радона в отвалах, чем в коренном залегании. Из земных глубин радон может поступать по зонам тектонических нарушений и карстовых проявлений, через незатампонированные буровые скважины, а также с подземными водами.

Обнаружение аномальных зон интенсивного выделения радона в атмосферу возможно по геологическим показателям в комплексе с пря- 
мыми измерениями эманирования радона горными породами или накопления их образцами в замкнутом пространстве. $\mathrm{K}$ настоящему времени доказано, что коренные породы и залегающие на них почвы являются источниками аномально высоких концентраций радона. Гелиеносные, радоновые и другие воды требуют дополнительной оценки, как и радононосность зон тектонических нарушений и карста.

Изучение выделения радона и прогноз его накопления в помещениях не могут быть ограничены оценкой радоноопасности строительных материалов и конструкций. Необходим учет комплекса геологических факторов.

Недопустимо высокие концентрации радона в помещениях необходимо устранять либо предотвращать с помощью архитектурных и конструктивных решений с учетом конкретной геологической ситуации на месте будущего строительства, путем регулирования режима эксплуатации или даже реконструкции существующих помещений.

Предотвращение недопустимого скопления радона в помещениях возможно лишь при условии знания геологических условий, радононосности горных пород, почв, рыхлых отложений и строительных материалов, а также подземных вод.

Необходимо дальнейшее проведение исследований и составление прогнозной карты радоноопасности ландшафта всей Эстонии.

\section{ЛИТЕРАТ У РА}

Булдаков Л. А. 1986. Человек и радиация. - Наука и жизнь, 9, 72-75.

Газизов М. С. 1989. О причинах повышенной радиоактивности зон закарстованных разрывных нарушений в Северной Эстонии и мероприятиях по их профилактике. - В кн.: Технология и комплексная механизация добычи горючих сланцев. Тр. ИГД им. А. А. Скочинского. Москва, 71-79.

Дричко В. Ф., Крисюк Б. Э., Травникова И. Г., Лисаченко Э. П., Дубенская М. А. 1977. Частотное распределение концентраций радия- 226 , тория- 228 и калия- 40 в различных почвах. - Почвоведение, 9, 75-80.

Крисюк Э. М., Лихтаров И. А. 1991. Ограничение облучения населения от природных источников ионизирующего излучения. Временные критерии для организации контроля и принятия решений. Минздрав СССР, Москва, 2-18.

Крисюк Э. М., Шалак Н. И., Королева Н. А. 1982. Определение концентраций радона в воздухе путем сорбции на активированном угле и измерение активности на гамма-спектрометре. - В кн.: Радиационная гигиена. НИИРГ, Ленинград, 125.

Лисаченко Э. П., Королева Н. А., Наумов Б. Е. 1984. Определение коэффициентов эманирования нарушенных диктионемовых сланцев. - В кн.: Достижения и задачи радиобиологических исследований в обеспечении радиационной безопасности человека и окружающей среды. УНЦ, Свердловск, 22.

Мосинец В. Н., Сорока Ю. Н., Молчанов А. И. 1991. Жилищное строительство в районах расположения горных предприятий и вопросы радиационной безопасности. - Горный ж., 7, 58-60.

Наумов Б. Е. 1990. О радоновой составляющей радиационного фона при добыче фосфоритов и сланцев. - В кн.: Проблемы экологической геологии в Прибалтике и Белоруссии. Тез. докл. ЛитНИГРИ, Вильнюс, 132-134. 
Принципы нормирования облучения населения от естественных источников ионизирующих излучений. 1986. Доклад Международной комиссии по радиационной защите (МҚРЗ), 39. Энергоатомиздат, Москва, 5-19.

Радиация: дозы, эффекты, риск. 1988. Мир, Москва, 1-20.

Рамзаев П. В. 1989. Риск реальный и мнимый. - В кн.: Межведомственный совет по информации и связям с общественностью в области атомной энергии, 8. ЦОИ, Москва, 1-16.

Tuбар K. 1987. Закономерности распределения гелия в подземных водах северного склона Прибалтийского артезианского бассейна. Автореф. канд. дис. Минск.

Шалак Н. И., Терентьев М. В., Крисюк Э. М., Шалаев И. Л. 1982. Исследование радиационной обстановки в неурановых шахтах и других подземных сооружениях. Реф. обзор. НИИРГ, Минздрав РСФСР, Ленинград, 5-17.

Juntunen, R. 1991. Etelä-Suomen kallioporakaivojen uraani- ja radiotutkimukset. Geologian tutkimuskeskus, Espoo, 10-21.

Jögioja, E., Rohumäe, T., Pahapill, L. 1990. A Note on the Indoor Radon Measurements in Estonia. Estonian Building Research Institute, Dept. of Building Physics, 4. Tallinn.

Lahermo, P., Juntunen, R. 1991. Radiogenic properties of Finnish soils and groundwaters. - В кн.: Pulkkinen, E. (ред.). Environmental Geochemistry in Northern Europe. Geologian tutkimuskeskus, Espoo, 257-268.

Piispanen, R. 1991. Current problems of environmental atmogeochemistry. - В кн.: Pulkkinen, E. (ред.). Environmental Geochemistry in Northern Europe. Geologian tutkimuskeskus, Espoo, 277-289.

Поступила в редакцию

6/XI 1992

Boriss NAUMOV, Väino PUURA, Vello KARISE, Nadežda KOROLJOVA, Mihhail TERENTJEV, Anna KOLOTVINA

\section{RADOONI OSA POHJA-EESTI ASULATE RADIATSIOONIFOONI KUJUNEMISEL (OKOGEOLOOGILINE ASPEKT)}

Artiklis on iseloomustatud Eesti kivimeid ja muldi lähtudes uraani- ja raadiumirea elementide sisaldusest neis ning piirkonna konkreetsetest geoloogilistest tingimustest. Saadud näitajaid on võrreldud Venemaa, Kesk-Aasia ja Soome mõnede piirkondade omadega. On käsitletud Eesti anomaalsete piirkondade (Pöhja-Eesti Narvast Tallinnani) kivimite kiirgusdoosi intensiivsust ja radionukliidide sisaldust ning loetletud radionukliidide sisalduse seisukohalt potentsiaalselt ohtlikud alad Eestis (Lääne-Eestis KilingiNömme-Pärnu-Matsalu piirkond, Peipsi-Pihkva järve ääres Mustvee-Räpina-Värska piirkond, samuti Tartu ümbrus ja Lääne-Eesti saared). On esitatud radooni kontsentratsiooni mõõtmise tulemused Tallinna, Maardu, Kohtla-Järve, Sillamäe ja Narva allmaarajatiste ning elu- ja tööruumide õhus. Radooni sisaldus ruumides, eriti keldrites, on kümneid kuni sadu kordi suurem kui välisõhus. On hinnatud radooni osa elanikkonna poolt saadavas summaarses efektiivses ekvivalentses kiirgusdoosis (Tallinna-MaarduUlgase piirkonnas on see $27-39 \%$, Kohtla-Järve-Sillamäe-Narva piirkonnas $61-93 \%$ ) ja esitatud Pōhja-Eesti linnade rajatistes paiknevate ruumide protsentuaalne jaotumus vastavalt radoonikontsentratsiooni skaalale. 
Boris NAUMOV, Väino PUURA, Vello KARISE, Nadezhda KOROLYOVA, Mikhail TERENTYEV, and Anna KOLOTVINA

\section{THE SHARE OF RADON IN THE FORMATION OF RADIATION BACKGROUND IN NORTH-ESTONIAN SETTLEMENTS (ECOGEOLOGICAL ASPECT)}

The formation of natural and artificial radiation background is investigated by specialists of different fields. Ecogeology studies the relations between the radiation background and the structure of the bowels of the earth.

The paper presents data on the emanation of radon in Estonian rocks and soils. The emanation rate depends on the concentration of elements of uranium and radium series in rocks and soils, but also on the geological conditions in every particular region. Comparison is drawn with some regions of Russia, Central Asia, and Finland. Radiation dose intensity and radionuclides content of rocks in anomalous regions of Estonia and Finland are discussed. The regions which could pose a threat to inhabitants of Estonia in terms of radon exhalation are listed. Radon concentration was measured in the air of several underground structures as well as dwelling houses and workrooms in Tallinn, Maardu, Kohtla-Järve, Sillamäe, and Narva. It is shown that radon-evoked effective equivalent doses depend on the type of construction and the duration of exposure. The share of radon in the total effective equivalent dose received by people is assessed. The distribution (\%) of rooms in some buildings of North-Estonian towns based on different radon concentrations is given.

Radon emanation intensity in soils and rocks depends on several factors, including the concentration of radionuclides, the occurrence of tectonic disturbances and cracks, karst phenomena, and the porosity of rocks, but also on the internal tension of the geological massif caused by Fennoscandia's neotectonic uplift.

In the Cambrian and Ordovician sedimentary rocks of North Estonia, first of all in graptolitic argillites, limestone, Obolus conglomerate, and glauconitic sand, which are responsible for the exhalation of radon, the concentration of radon-226 was found to be $2.2-5.9$ to $8-9$ times higher than in their analogues in the regions compared. Granites of Finland with a still higher radon concentration were the only exception.

The region between Tallinn and Narva in North Estonia poses the greatest threat in terms of radon emanation. In this region the concentration of radionuclides in rocks is anomalously high. Other hazardous regions are Kilingi-Nõmme-Pärnu-Matsalu in West Estonia, Mustvee-Räpina-Värska at Lake Peipsi-Pihkva, the surroundings of Tartu, and the West-Estonian Archipelago where the concentration of helium has heightened in ground water or rocks.

Measurements conducted in the basements or excavations to a depth of $3 \mathrm{~m}$ below land surface showed that the amount of radon emanated by soils and rocks was the highest in the eastern part of Estonia between Kohtla-Järve and Narva, and it was somewhat lower in the west, in the area of Tallinn and Maardu: from $1758-2180 \mathrm{~Bq} / \mathrm{m}^{3}$ to $3430 \mathrm{~Bq} / \mathrm{m}^{3}$, and from $252-1715 \mathrm{~Bq} / \mathrm{m}^{3}$ to $3404 \mathrm{~Bq} / \mathrm{m}^{3}$, respectively. These figures are $132-439$ times higher than the corresponding indicator in the air near land surface. In terms of the latter indicator, North Estonia surpasses Novgorod, a region with similar climate, and approaches Bishkek, an area of granite stones in mountainous Kyrgyzstan.

In comparison with underground constructions, radon concentration on the ground floor of overground buildings is ca. 24 times lower (from $25-57 \mathrm{~Bq} / \mathrm{m}^{3}$ to $300 \mathrm{~Bq} / \mathrm{m}^{3}$, which is, however, 43 times as much as in the open air), while on the upper floor it is 70 times lower (from $8-45 \mathrm{~Bq} / \mathrm{m}^{3}$ to $100 \mathrm{~Bq} / \mathrm{m}^{3}$, i. e. 14 times higher than in the open air).

In different regions the concentration of radon in the living and working rooms was higher than $50 \mathrm{~Bq} / \mathrm{m}^{3}$ in $24-71 \%$ of cases, higher than $100 \mathrm{~Bq} / \mathrm{m}^{3}$ in $9-57 \%$ of cases, and higher than $200 \mathrm{~Bq} / \mathrm{m}^{3}$ in $17-43 \%$ of cases.

The effective radiation dose received by people whose working place is in the basement is four and more times higher than the total permissible dose $(5 \mathrm{mSv} / \mathrm{yr})$. The sole source is radon and its daughter elements. In the overground buildings the dose is from 
$0.4-1.6$ to $3.8 \mathrm{mSv} / \mathrm{yr}$ (from $8-32$ to $39-76 \%$ of the total permissible dose), reaching occasionally $20.6-39 \mathrm{mSv} / \mathrm{yr}$.

In terms of radon accumulation and impermissible radiation, the most dangerous for people are the rooms in the basement, on the ground floor (sometimes even on the first floor), and also the buildings during whose construction Lower-Ordovician limestone or graptolite-argillite beds were opened, limestone buildings, and buildings whose foundation lies immediately on the soil with poor ventilation.

The studies suggest that in the future the inhabitants of North Estonia may receive even higher doses in connection with (1) the occupation of basements by enterprises and individuals without preliminary dosimetric control, (2) the need to insulate the rooms, as a result of which they become more difficult to ventilate, and (3) the construction of dwelling houses, enterprises, greenhouses, etc., in anomalous regions not earlier detected by radiation studies. 